\title{
INOVAÇÃo TECNOLÓGICA E PRODUÇÃo NO SETOR QUÍMICO
}

\author{
Maria Vitória G. Miron*, Flávio do Couto Bezerra Cavalcanti e Pedro Wongtschowski
}

Oxiteno S/A Indústria e Comércio, Av. Brigadeiro Luis Antonio, 1343, 01317-910 São Paulo - SP

\begin{abstract}
TECHNOLOGICAL INNOVATION AND PRODUCTION IN THE CHEMICAL SECTOR. Innovation is the main tool for competitiveness and growth in the chemical sector and the main factors for innovation activities in industry as well as the innovation dynamics are discussed in this paper. Success indicators of innovation in Oxiteno are the following: $54 \%$ of the current production derives from RD\&E projects, $11 \%$ of the gross margin in the internal market is due to new products, the company is a technology licensor, holding 17 patents and keeping a strong participation in the production and service sales in the high technology catalysts area, beyond its core petrochemicals and surfactants area.
\end{abstract}

Keywords: innovation factors; innovation dynamics; indicators for success in innovation.

\section{INTRODUÇÃO}

A indústria química tem uma grande importância no contexto econômico brasileiro e mundial. Ela é fornecedora de matériasprimas para outras indústrias e insumos para produtos utilizados por consumidores em uma ampla gama de segmentos de negócios de diversas naturezas, como produtos farmacêuticos; higiene pessoal, perfumaria e cosméticos; sabões e detergentes; embalagens; vestuário; defensivos agrícolas; adubos e fertilizantes; tintas, esmaltes e vernizes etc.

Quadro 1. Percentagem de participação de Produtos Químicos nas formulações para os segmentos

\begin{tabular}{ll}
\hline Tintas & 94 \\
Controle de Pestes & 87 \\
Adesivos e Selantes & 85 \\
Medicina & 84 \\
Produtos de Limpeza & 75 \\
Cosméticos & 68 \\
Agricultura & 30 \\
Veículos Automotores & 16 \\
\hline
\end{tabular}

O faturamento da indústria química mundial em 2003 foi US $\$ 1,9$ trilhões e o setor de produtos químicos no Brasil é o segundo em importância na formação do PIB industrial, com um faturamento de US\$ 45 bilhões no mesmo ano.

A inovação é a principal ferramenta no setor químico para manutenção de sua competitividade e para seu crescimento, seja através da melhoria da qualidade de seus produtos, de seus processos e serviços, da redução de seus custos de produção e, fundamentalmente, do lançamento de novos produtos ou produtos customizados atendendo a requisitos definidos.

"Inovação é o uso comercialmente bem sucedido de uma invenção" - Frank R. Bacon

\section{FATORES QUE INFLUENCIAM A INOVAÇÃO TECNOLÓGICA}

O sucesso da inovação tecnológica nas empresas depende de fatores que assegurem um ambiente propício ao investimento em

*e-mail: vitoria.miron@oxiteno.com.br
Quadro 2. A Indústria Química Nacional

\begin{tabular}{cccc}
\hline $\begin{array}{c}\text { Rank } \\
\text { PIB }\end{array}$ & $\begin{array}{c}\text { Rank } \\
\text { Químico }\end{array}$ & País & $\begin{array}{c}\text { Vendas Químicas } \\
\text { (US\$ bilhões) }\end{array}$ \\
\hline 1 & 1 & EUA & 458 \\
2 & 2 & Japão & 201 \\
3 & 3 & Alemanha & 154 \\
7 & 4 & China & 118 \\
5 & 5 & França & 99 \\
6 & 6 & Itália & 74 \\
14 & 7 & Coréia & 60 \\
4 & 8 & Reino Unido & 55 \\
18 & 9 & Bélgica & 50 \\
12 & 10 & Brasil & 45 \\
\hline
\end{tabular}

pesquisa e desenvolvimento. A Figura 1 apresenta os principais fatores.

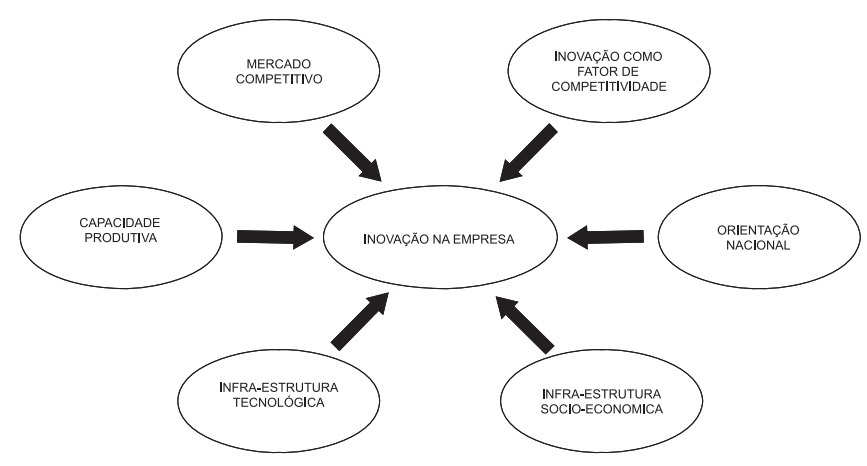

Figura 1. Fatores que influenciam a inovação

\section{Mercado competitivo}

A abertura do mercado interno para a importação força os produtores locais a serem mais inovadores para manter padrões globais de preço, qualidade e performance de seus produtos. As empresas exportadoras, pela acirrada concorrência, necessitam primordialmente serem inovadoras para poder ter sucesso. 


\section{Inovação como fator de competitividade}

As empresas, almejando a liderança do mercado, utilizam a inovação para otimizar seus processos e solucionar problemas com maior rapidez.

\section{Orientação nacional}

Necessitam-se políticas governamentais que privilegiem o desenvolvimento de tecnologia e estimulem parcerias entre os setores público e privado, promovendo a inovação nos países. Os mecanismos para que a indústria se desenvolva, como por ex., o fornecimento de recursos financeiros, devem também ser de longo prazo para dar continuidade ao processo de inovação e fomentar o espírito empreendedor.

\section{Infra-estrutura sócio-econômica}

Devem existir no país instituições sociais e econômicas que suportem e mantenham os recursos físicos, humanos, organizacionais e econômicos essenciais para a existência de empresas baseadas em tecnologia, tais como mercados de capital dinâmicos, tendência ascendente na formação de capitais, investimento de capital externo e investimento em educação.

\section{Infra-estrutura tecnológica}

As instituições sociais e econômicas do país devem contribuir diretamente para o desenvolvimento, a produção e a comercialização de novas tecnologias. A inovação é facilitada pela existência de um sistema de proteção de direitos de propriedade intelectual, projetos de pesquisa e desenvolvimento voltados à industrialização, competência em produção de alta tecnologia e capacidade de formar e absorver cientistas e engenheiros qualificados.

\section{Capacidade produtiva}

As empresas devem ter o domínio de suas tecnologias de operação e processos, com instalações industriais adequadas a essas tecnologias, recursos humanos capacitados a compreendê-las e melhorá-las, além de serem suportadas por práticas modernas de gerenciamento. Esse domínio é o alicerce das atividades inovadoras.

\section{AVALIAÇÃO DOS FATORES DE INOVAÇÃO TECNOLÓGICA NA INDÚSTRIA QUÍMICA BRASILEIRA}

Para compreendermos as razões dos baixos níveis de inovação tecnológica na indústria química brasileira, será feita uma análise de cada um dos fatores que a influenciam, de acordo com o modelo proposto no item anterior.

\section{Mercado competitivo}

No início dos anos 90 foi introduzida a abertura comercial na economia brasileira e, em razão disso, as empresas passaram por processos de reestruturação, buscando o aumento de sua competitividade, através de exportações, mudanças organizacionais, redirecionamento de portfólios de mercados e produtos. Entretanto, o que aparentemente poderia ser considerado fator positivo à inovação teve o efeito reverso. Em um ambiente de baixo crescimento e política macro-econômica focada em juros altos, a abertura descontrolada fez com que inúmeros centros de $\mathrm{P} \& \mathrm{D}$ de empresas brasileiras e de multinacionais fossem fechados, priorizando a importação de tecnologias e processos.

\section{Inovação como fator de competitividade}

De modo geral, os empresários e dirigentes de empresas industriais brasileiras não reconhecem a inovação tecnológica como ferramenta estratégica para manutenção e crescimento de seus negócios. As empresas que mais investem em tecnologia o fazem motivadas pela conquista, manutenção e ampliação de seus mercados e sua liderança é que define a intensidade do esforço de inovação.

\section{Orientação nacional}

Segundo estudo recente do IBGE, as despesas com pesquisa e desenvolvimento no Brasil no ano de 2000 foram 1,07\% do PIB, sendo o setor público responsável por $63 \%$ dessas despesas. Nos países membros da Organização para Cooperação e Desenvolvimento Econômico - OCDE os resultados foram 2,2 e 37\%, respectivamente. Por essa distribuição de dispêndio verifica-se que as atividades de $\mathrm{P} \& \mathrm{D}$ no Brasil são preponderantemente conduzidas por instituições públicas de ensino e de pesquisa, ao contrário da grande maioria dos outros países.

A Tabela 1 mostra indicadores de inovação no Brasil da pesquisa do IBGE, no período de 1998 a 2000.

Tabela 1. Indicadores de inovação no Brasil

\begin{tabular}{lcc}
\hline Indicador & $\begin{array}{c}\text { Conjunto } \\
\text { de Empresas } \\
\text { Brasileiras }\end{array}$ & $\begin{array}{c}\text { Fabricação } \\
\text { de Produtos } \\
\text { Químicos }\end{array}$ \\
\hline $\begin{array}{l}\text { Taxa de Inovação } \\
\text { (porcentagem de empresas }\end{array}$ & 31,5 & 46,1 \\
$\begin{array}{l}\text { inovadoras em relação ao } \\
\text { número total de empresas) }\end{array}$ & & \\
$\begin{array}{l}\text { Intensidade de P\&D } \\
\text { (relação entre os gastos } \\
\text { de P\&D e a receita líquida } \\
\text { de vendas) }\end{array}$ & 0,64 & 0,65 \\
\hline
\end{tabular}

Verifica-se que o setor químico brasileiro é mais inovador que a média das empresas brasileiras, criando a oportunidade de avanços no conhecimento técnico e científico. Por outro lado, os gastos em $\mathrm{P} \& \mathrm{D}$ são similares à média das empresas brasileiras, porém muito abaixo dos patamares internacionais de investimento, que chegam a ser dez vezes superiores, para esse segmento.

Além da conjuntura brasileira não facilitar a inovação tecnológica, inexistem mecanismos específicos de desenvolvimento tecnológico de incentivo à indústria química, como por ex., os fundos setoriais existentes para outros segmentos industriais, que não somente o de petróleo.

\section{Infra-estrutura sócio-econômica}

O ambiente macroeconômico brasileiro é desfavorável aos investimentos, principalmente, em inovação tecnológica, que têm um grau elevado de incerteza. As altas taxas de juros vigentes, as leis trabalhistas inadequadas à atual dinâmica econômica, dentre outros fatores, levam à inibição dos investimentos, a um mercado de capitais restrito com baixo investimento em atividades produtivas.

O grande risco de baixos investimentos é a perda contínua de competitividade, face à grande maioria dos países tecnologicamente mais competitivos, que têm incentivos à inovação tecnológica mais eficazes. 


\section{Infra-estrutura tecnológica}

Os investimentos das últimas décadas nas universidades propiciaram uma oferta de recursos humanos de alto nível no país. Além disso, houve um crescimento considerável na participação da produção científica no cenário internacional. Porém, a ênfase ainda reside na publicação de artigos (produção do conhecimento) e não em patentes (uso do conhecimento), resultando em um atraso tecnológico que é representado pela baixa participação de produtos de alta tecnologia na pauta de exportações brasileiras.

Dado seu forte conteúdo tecnológico, o segmento químico possui os recursos humanos com alto nível de qualificação, mostrando a necessidade de continuarmos formando profissionais capacitados para, no mínimo, manter a taxa de inovação nas empresas, mas faltam mecanismos que facilitem a presença destes profissionais nas empresas.

\section{INOVAÇÃO TECNOLÓGICA NAS EMPRESAS QUÍMICAS}

A inovação tecnológica tem como característica a incerteza, que é a obtenção de resultados que podem tanto ser de sucesso quanto de fracasso, e a demanda de tempo e recursos financeiros. O sucesso da empresa nessa atividade depende principalmente da crença de sua alta administração na importância da inovação como fator de competitividade, na disponibilidade de recursos e na existência de um sistema de gestão eficiente. A inovação deve ter papel chave na estratégia de longo prazo na empresa, com valorização do conhecimento.

Uma gestão eficiente da inovação na empresa requer uma estruturação interna de seus recursos, com metodologias e ferramentas para não apenas coordenar suas atividades internas, mas também as de todos os participantes externos à empresa.

No âmbito interno, um modelo de gestão deve contemplar critérios para captação de idéias, seleção e priorização de projetos de desenvolvimento, seleção de alianças e parcerias com universidades, institutos de pesquisa, fornecedores e clientes e, principalmente, o claro alinhamento da atividade tecnológica com a estratégia da empresa. Adicionalmente, a empresa deve estar atenta a fontes de financiamento e ter forte atuação junto a órgãos governamentais, visando defender os interesses da empresa em inovação.

No âmbito externo, que é fundamental para o processo de inovação tecnológica na empresa química, cada participante tem competências específicas que, gerenciadas de modo eficiente, trarão resultados positivos para todos.

A Figura 2 mostra os participantes do processo de inovação da empresa e, a seguir, serão avaliadas as sinergias entre eles e a empresa, com recomendações para uma melhor interação.

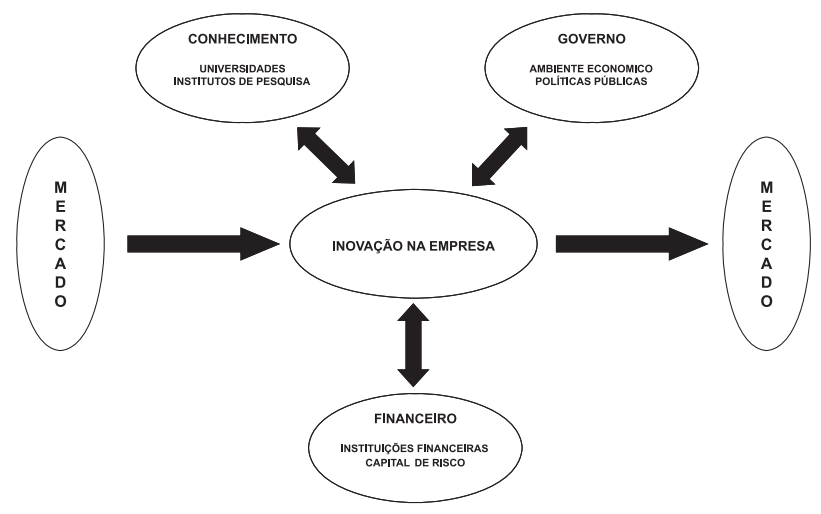

Figura 2. O processo de inovação

\section{Mercado}

O processo inicia-se pelas demandas do mercado por novas soluções ou por produtos de custo menor, qualidade e performance maiores. Essas demandas podem vir de projetos em parceria com fornecedores e clientes e pelas oportunidades de mercado, identificadas pela empresa no seu processo de planejamento estratégico. Com os fornecedores de insumos visa-se obter matérias-primas mais competitivas no desenvolvimento ou otimização de produtos e processos, e com fornecedores de equipamentos, novas tecnologias que levem a projetos com menor investimento e que minimizem a geração de efluentes. $\mathrm{O}$ relacionamento estreito com os clientes permite o desenvolvimento de produtos que irão reforçar os mercados desses clientes.

O processo de inovação termina no mercado com a comercialização dos produtos demandados.

\section{Conhecimento}

Os parceiros da empresa em tecnologia são as universidades e os institutos de pesquisa. As expectativas da empresa sobre o papel da universidade nesse processo são: sua função básica é a formação de pessoas que irão desenvolver atividades que gerem inovação tecnológica, na academia, nos institutos de pesquisa ou nas empresas; pesquisa aplicada, onde são identificadas e criadas aplicações dos conhecimentos obtidos em pesquisa básica, que podem gerar novas oportunidades para as empresas ou aperfeiçoar seus processos produtivos; trabalhos em transferência de tecnologia através de agências de inovação, onde se estimula inclusive o empreendedorismo e, formação de centros de excelência, para projetos em parceria e incubação de pequenas empresas.

As oportunidades de parcerias com os institutos de pesquisa são: condução de pesquisa aplicada, podendo também contar com uma parceria com a universidade; condução do desenvolvimento ou do aperfeiçoamento de produtos e processos em escala piloto, ou softwares de simulação de processo e, apoio às empresas em soluções de problemas técnicos.

Atualmente há disponível nas universidades e centros de pesquisa uma grande quantidade de conhecimento em estoque, que pode ser utilizado pelas empresas.

Há espaço para melhorias neste processo, tais como solucionar o conflito de interesses no tema confidencialidade das informações, dado que tanto universidades quanto centros de pesquisa precisam publicar seus trabalhos e as empresas, via de regra, querem mantê-los confidenciais; melhorar o entendimento entre as partes quanto à importância de metas e prazos de entrega dos trabalhos, dado que a dinâmica do mundo empresarial é diferente da dinâmica do mundo acadêmico e, aumentar a produção de patentes (uso do conhecimento) pelas Universidades e Institutos Tecnológicos, em sintonia com a estratégia das empresas.

\section{Governo}

Como exposto no item Infra-estrutura socioeconômica, a inovação é fortemente influenciada pelo ambiente macroeconômico. É fundamental que o direcionamento governamental seja de longo prazo e que englobe ações como revisão do sistema tributário para que os investimentos em tecnologia não sejam onerados e para que seja permitido às empresas competirem em condições de igualdade no mercado externo; aprimoramento da abertura comercial, através de uma participação agressiva do governo brasileiro junto a organismos internacionais de comércio, para criar condições justas de comercialização de produtos e, melhorar a operacionalização 
dos instrumentos de política (financiamento) governamental para torná-los mais explícitos, sem descontinuidades, para diminuir a burocracia para sua implantação e permitir maior participação de pequenas e médias empresas na cadeia de inovação tecnológica nas empresas.

Enfim, precisamos de políticas públicas claras, acessíveis e perenes no incentivo à Ciência e Tecnologia.

\section{Financeiro}

Como a atividade tecnológica é um investimento de risco, uma das formas de financiamento é através de agências e bancos governamentais, que foram criados para fomentar o desenvolvimento tecnológico, na maioria das vezes incentivando a parceria entre empresas, universidades e institutos de pesquisa. A FINEP é a principal agência de concessão de financiamento, com retorno, às atividades de PD\&E e outros esforços de inovação para a indústria brasileira, através de diversos programas. Existem outras fontes de financiamento para projetos de natureza tecnológica, dentre as quais podemos citar BNDES, Fundos Setoriais, de Infra-Estrutura e de Interação Universidade-Empresa (Verde-Amarelo). Apesar de todas estas opções, seu domínio/operacionalização é ainda difícil para a maioria das empresas.

O capital de risco é um instrumento bastante utilizado na economia americana e constitui-se em financiamento de longo prazo a empreendimentos de base tecnológica, cujos altos riscos são compensados pela expectativa de ganhos elevados. No Brasil é uma atividade incipiente, com muito poucas fontes de financiamento seja governamental ou privado, sendo as mais conhecidas o "Projeto Inovar" da FINEP e a Venture Capital da Votorantim em biotecnologia. Entretanto, as condições macroeconômicas ainda o tornam um instrumento bastante restrito para a indústria química.

\section{O MODELO DE GESTÃO DA INOVAÇÃO NA OXITENO}

A Oxiteno é uma das maiores companhias químicas do país, que atua no setor químico e petroquímico, colocando boa parte de seus produtos no mercado interno. Tem, também, importante presença no mercado externo, destinando seus produtos para o Extremo Oriente, o Mercosul, a Europa, os Estados Unidos e a África do Sul.

Sua produção engloba óxido de eteno, etilenoglicóis, éteres glicólicos, etanolaminas, metil-etil-cetona, tensoativos e especialidades químicas, atendendo a mais de 30 segmentos de mercado, destacando-se os de agroquímicos, alimentos, cosméticos, couros, detergentes, embalagens para bebidas, fios e filamentos de poliéster, fluidos para freio, petróleo e tintas e vernizes.

Desde sua origem, a Oxiteno considerou a capacitação tecnológica como um fator estratégico para manter sua competitividade e sustentar o seu crescimento.

Em uma primeira fase houve o domínio operacional de tecnologias adquiridas, seguindo-se ao domínio dos processos praticados. Nessa etapa já eram realizadas atividades de otimizações dos processos existentes e iniciados trabalhos em parceria com universidades para aumento de capacitação. Ao mesmo tempo foram iniciadas as atividades de Engenharia de Processo e Engenharia Básica em projetos de novas unidades produtivas, conduzidos por pessoal interno, utilizando os conhecimentos previamente adquiridos.

A capacitação adquirida permitiu o início das atividades estruturadas de $\mathrm{P} \& \mathrm{D}$, com desenvolvimento de aplicações, produtos e processos, alocação de pessoal qualificado, infra-estrutura em laboratórios e metodologias de trabalho, incluindo-se a busca de recursos financeiros nas agências de fomento.
A Oxiteno utiliza a metodologia do "Balance Score Card (BSC)", desenvolvida pelos renomados Profs. Robert Kaplan e David Norton, para explicitar e operacionalizar sua estratégia empresarial. O produto final da metodologia é o que chamamos de mapa estratégico, onde objetivos são definidos e associados a indicadores e metas para acompanhamento dos resultados (Figura 3).

\begin{tabular}{|c|c|c|c|}
\hline $\begin{array}{l}\text { Perspectiva } \\
\text { Financeira }\end{array}$ & Crescimento & $\$$ & Excelência Operacional \\
\hline $\begin{array}{l}\text { Perspectiva } \\
\text { de Mercado }\end{array}$ & & Clientes & \\
\hline $\begin{array}{l}\text { Perspectiva } \\
\text { Interma }\end{array}$ & \multicolumn{3}{|l|}{$\begin{array}{c}\text { Adequar estrutura } \\
\text { produtiva } \\
\text { para sustentar } \\
\text { o crescimento }\end{array}$} \\
\hline $\begin{array}{c}\text { Perspectiva } \\
\text { de } \\
\text { Aprendizado } \\
\text { Crescimento }\end{array}$ & & $\begin{array}{c}\text { Possibilitar } \\
\text { o Desenvolvimento } \\
\text { as Competências Crit }\end{array}$ & \\
\hline
\end{tabular}

Figura 3. Mapa estratégico

Desta forma, Inovação Tecnológica está explicitamente inserida no BSC, na Perspectiva Interna tendo como objetivo estratégico "desenvolver novos produtos, aplicações e mercados", com seu respectivo indicador de desempenho e meta a ser atingida nos próximos anos.

Atualmente, $2 \%$ do faturamento anual é investido nas atividades de pesquisa e desenvolvimento de aplicação, produtos e processos, valor muito acima dos praticados pelo segmento no Brasil.

O Sistema de Gestão da Inovação, com a forte visão do mercado tem sua configuração apresentada na Figura 4.

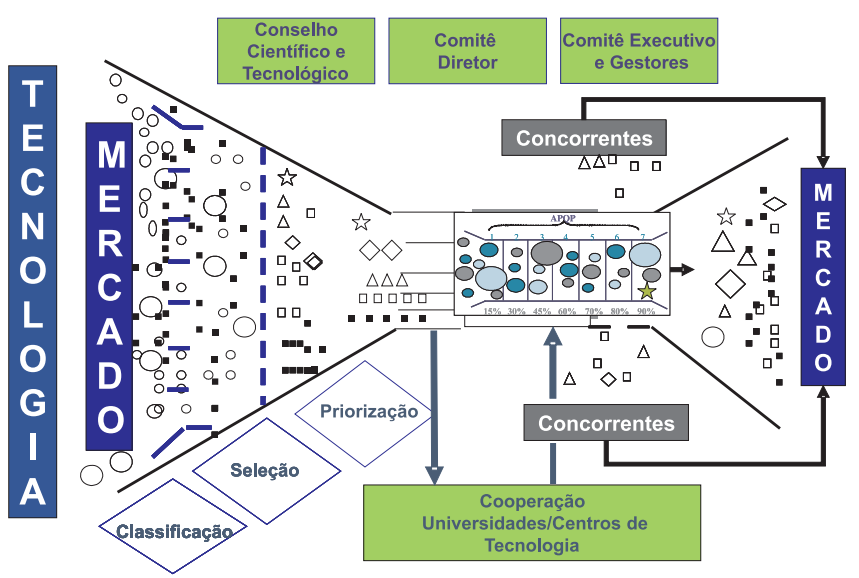

Figura 4. Sistema de gestão da inovação

O processo de inovação é gerido pelo Comitê Diretor, com apoio do Conselho Científico e Tecnológico, que tem especialistas de renomado conhecimento, oriundos tanto da Academia quanto da Indústria.

O Conselho Científico e Tecnológico reúne-se anualmente, tendo como missão contribuir para a atualização da Oxiteno nas tendências tecnológicas em seu negócio; identificar oportunidades de projetos de desenvolvimento em parceria com universidades/institutos de pesquisa, tanto no Brasil quanto no exterior; identificar e propor oportunidades de negócios e, analisar criticamente a carteira de projetos, avaliando seus resultados, seu conteúdo tecnológico (potencial retorno financeiro e nova plataforma de conhecimento) e o balanceamento de projetos no curto, médio e longo prazos. 
O Comitê Diretor tem como principais responsabilidades: elaboração, implantação e monitoramento das diretrizes para PD\&E, assim como seu alinhamento às diretrizes da empresa; definição do nível de capacitação e competências que se deseja para PD\&E; dimensionamento e alocação de recursos para PD\&E; definição de metas e acompanhamento dos resultados para PD\&E e, estabelecimento de diretrizes para proteção e propriedade industriais.

$\mathrm{O}$ processo de desenvolvimento de atividades em inovação da Oxiteno é executado pelo Comitê Executivo e Gestores de áreas e tem como entrada projetos propostos no Planejamento Estratégico. A seguir, os projetos são selecionados e priorizados por este Comitê Executivo e conduzidos pelas áreas que operacionalizam as atividades em PD\&E, que as organizam buscando os recursos necessários para execução da carteira de projetos.

Os projetos em parceria com Universidades visam a prospecção de novas tecnologias e a capacitação em áreas de conhecimento novas para a empresa, fundamentais nos projetos de longo prazo. A título de exemplo, CENPES, COPPETEC, EPUSP, IPT, IQ-USP, ITAL, UFBA, UFRGS, UFSCar, UNESP e UNICAMP atuaram e atuam como parceiras da Oxiteno nos projetos de inovação.

Como resultados desse esforço em inovação, temos como alguns exemplos de indicadores da empresa:

- $54 \%$ da produção atual provém de projetos de PD\&E;

- $11 \%$ da margem bruta no mercado interno provêm de novos produtos;
- a Oxiteno licencia tecnologias para terceiros;

- 17 patentes concedidas e,

- produção e vendas de serviços em catalisadores, segmento com demanda de alto conteúdo tecnológico.

O sucesso das atividades em Inovação é a coroação de uma postura empresarial que acredita na importância do desenvolvimento tecnológico e que se inicia com o clima propício para geração de idéias dentro da própria empresa, apoiado por uma sistemática de captação, avaliação e "feed-back". Diferentes áreas da empresa, que detêm competências diferenciadas, contribuem de forma integrada neste processo. Garante-se, assim, um fluxo contínuo de idéias para avaliação o qual, por sua vez, assegura um fluxo contínuo de projetos de PD\&E que se materializam em soluções inovadoras e sustentam o resultado do negócio.

\section{REFERÊNCIAS}

1. Associação Nacional de Pesquisa, Desenvolvimento e Engenharia das Empresas Inovadoras (ANPEI); Como Alavancar a Inovação Tecnológica nas Empresas, São Paulo: Brasil, 2004.

2. National Science Board, Science and Engineering Indicators - 2002, Arlington, VA: National Science Foundation, 2002.

3. Booz, A. H.; O Futuro da Indústria Química no Brasil, (ABIQUIM) São Paulo, Brasil, 2003.

4. Patel, H.; Staying Competitive Trough Innovation: To Lead or to Follow?; Bulla,R.; PD\&E na Oxiteno, Apresentações da V Conferência ANPEI, Florianópolis, Brasil, 2005. 